\title{
Introdução a "Autonomia, Vulnerabilidade, Reconhecimento e Justiça" de Axel Honneth e Joel Anderson
}

\author{
Nathalie Bressiani \\ Doutoranda em Filosofia na USP.
}

\begin{abstract}
Resumo: 0 desenvolvimento de uma con- Abstract: The development of an alternative cepção alternativa de autonomia que account of autonomy that points to the aponte para a importância das relações de importance of recognition relations and reconhecimento e problematize de forma originally problematizes the individualist original 0 viés individualista de concep- bias of liberal accounts of autonomy is, by ções liberais de autonomia já é, por si só, itself, a theoretical undertaking that uma empreitada teórica que justifica a justifies the translation of "Autonomy, tradução de "Autonomia, Vulnerabilidade, Vulnerability, Recognition, and Justice" Reconhecimento e Justiça" para o portu- into Portuguese. This brief introduction, guês. Nosso objetivo com essa introdução however, aims to pinpoint that the é, contudo, ressaltar que a importância do relevance of this paper goes beyond that, artigo de Axel Honneth e Joel Anderson once it helps to clarify the position of its extrapola estes objetivos, pois explicita 0 authors on important issues within posicionamento de seus autores frente a contemporary political philosophy and outras questões de grande relevância no critical theory.
\end{abstract}

interior do debate contemporâneo sobre filosofia política e teoria crítica.

O artigo de Axel Honneth e Joel Anderson, "Autonomia, Vulnerabilidade, Reconhecimento e Justiça", traduzido para esse volume dos Cadernos de Filosofia Alemã, foi originalmente publicado em 2005 numa coletânea de artigos organizada por John Christman e Joel Anderson, Autonomy and the Challenges to Liberalism. New Essays, ${ }^{1}$ em que diversos autores discutem elementos que consideraram problemáticos

1. Anderson, J.; Christman, J.; Autonomy and the Challenges to Liberalism. New Essays. Cambridge: Cambridge University Press, 2005, pp. 127-149. 
na tradição do liberalismo. Nesse contexto, o artigo de Anderson e Honneth tem como objetivo apontar para o viés individualista das concepções liberais de autonomia, em que a não interferência é tomada como condição suficiente para a proteção da autonomia individual. De acordo com os autores, partindo de uma idealização enganosa, segundo a qual os indivíduos seriam autossuficientes e precisariam apenas obter independência de seus parceiros de interação para conseguirem se em penhar em sua própria busca pela felicidade, as concepções liberais de autonomia não dariam conta de abarcar as vulnerabilidades e carências dos seres humanos. Como afirmam,

os principais compromissos do liberalismo, salvaguardar a autonomia e proteger os vulneráveis, quando combinados com a ideia de que a autonomia é um conjunto adquirido de capacidades para conduzir a própria vida, exigem que a sociedade esteja preocupada em garantir não só a não interferência, como também as relações sociais que asseguram a autonomia. ${ }^{2}$

Honneth e Anderson assumem, portanto, um compromisso com a realização da autonomia individual, mas procuram mostrar que os autores liberais - e Rawls em particular - não a teriam levado às últimas consequências, pois ignoram algo que se coloca como central para sua efetivação: as relações sociais de reconhecimento. Os dois autores questionam, assim, a limitação das compreensões liberais de autonomia, que não conceitualizariam adequadamente a interdependência dos indivíduos, mas o fazem sem abrir mão do próprio compromisso liberal com a autonomia, entendida por eles como a capacidade de um indivíduo de conduzir a vida que determinou como digna de valor. Nesse sentido, ambos afirmam que as condições sociais para a realização da liberdade individual ultrapassam a mera não interferência e exigem a elaboração de uma concepção distinta e mais abrangente de autonomia do que aquelas defendidas pelos liberais.

Tendo isso em vista, Honneth e Anderson se colocam o objetivo de desenvolver uma concepção de autonomia que abarque as várias condições sociais necessárias para sua realização e para a proteção dos vulneráveis. Ao fazerem isso, eles se aproximam de autores que os

2. Honneth, A., Anderson, J., "Autonomia, Vulnerabilidade, Reconhecimento e Justiça". In: Cadernos de Filosofia Alemã. Crítica e Modernidade, v. 17, jan-jun de 2011, p. 82 . 
antecederam na tentativa de dar um maior conteúdo às exigências ligadas à autonomia pessoal, isto é, de autores que defendem que, além de não interferência, a realização da autonomia requer que os indivíduos disponham de um mínimo de recursos materiais e/ou condições institucionais adequadas. ${ }^{3}$ Honneth e Anderson procuram seguir o caminho aberto por esses autores, mas de outra forma: para ambos, ao defenderem a necessidade de que o rol das condições sociais requeridas para a realização da autonomia fosse ampliado, esses autores teriam explicitado os limites das concepções liberais de autonomia e de sua defesa da liberdade negativa, mas não os teriam superado.

Segundo Honneth e Anderson, nem os liberais nem os defensores de uma maior distribuição material teriam conceitualizado adequa damente a importância das relações sociais de reconhecimento recíproco para o desenvolvimento de formas positivas de autorrelação prática, sem as quais o indivíduo não tem condições para ser verdadeiramente autônomo. Para os dois autores, a realização da autonomia não exige apenas a não interferência ou mesmo direitos civis, políticos e sociais. Para que possam ser autônomos, afirmam, os indivíduos têm de ser reconhecidos por seus parceiros de interação em três diferentes esferas, regidas pelos princípios do amor, do respeito e da estima. Seria, de acordo com eles, apenas por meio da obtenção do reconhecimento nessas três esferas que os sujeitos seriam capazes de desenvolver sentimentos de autoconfiança, autorrespeito e autoestima, indispensáveis para que conduzam a vida que determinaram como digna de valor. Como afirmam Honneth e Anderson:

uma abordagem particularmente promissora situa a vulnerabilidade social dos agentes nos modos pelos quais estar apto a conduzir a própria vida depende de estar amparado por relações de reconhecimento. Resumidamente, a ideia central é a de que as competências

3. Essa empreitada se aproximaria, de certo modo, àquela assumida por Thomas Marshall, que mostra - a partir de uma reconstrução histórica da ampliação dos direitos na Inglaterra - como a efetivação dos direitos civis levou à criação de direitos político e sociais. Marshall, T. Cidadania, Classe Social e Status. Rio de Janeiro: Zahar Editores, 1969. Contudo, ela pode ser também pensada a partir dos trabalhos de John Ralws, autor que ressalta a importância da distribuição de recursos para que todos possam viver a vida que estabeleceram como boa. Cf. Rawls, J. Uma Teoria da Justiça. São Paulo: Martins Fontes, 2002. 
relativas a agentes e que compreendem a autonomia requerem que as pessoas sejam capazes de manter certas atitudes frente a si mesmas (em particular, autoconfiança, autorrespeito e autoestima) e que essas autoconcepções afetivamente preenchidas - ou, para usar a linguagem hegeliana, "autorrelações práticas" - são, por sua vez, dependentes das atitudes adotadas por outros. ${ }^{4}$

Contrapondo-se, dessa forma, tanto às concepções liberais de autonomia como àquelas desenvolvidas por autores que reforçam suas condições materiais ou institucionais, Honneth e Anderson ressaltam a importância da intersubjetividade para a realização da autonomia pessoal e procuram mostrar como sua abordagem, que parte das vulnerabilidades associadas às relações de reconhecimento, é mais adequada que as demais. Eles procuram, assim, elaborar uma concepção de autonomia baseada no reconhecimento, que conseguiria dar conta das carências, vulnerabilidades e interdependência dos indivíduos, até então negligenciadas.

Para elaborarem essa concepção relacional de autonomia, os autores retomam explicitamente algumas das principais teses da teoria do reconhecimento desenvolvida por Honneth. Eles se voltam, nesse sentido, a Luta por Reconbecimento ${ }^{5}$ e procuram partir da violação das relações de reconhecimento para mostrar, com base em seus efeitos negativos, o quão importantes elas realmente são para a autonomia. Analisando, nas partes III a V do artigo, os diferentes prejuízos causados à autonomia pelos rompimentos das relações sociais nas três esferas do reconhecimento, os autores procuram demonstrar a pretensão normativa da qual partem, a saber, "a de que a autonomia de um indivíduo é vulnerável a rompimentos em seus relacionamentos com os outros". ${ }^{6}$ Eles exploram, assim, um elemento que já se encontra em Luta por Reconbecimento, o desrespeito gerado pela violação de relações de reconhecimento, mas o fazem ressaltando um aspecto antes apenas indicado: a relação entre a garantia das três formas de reconhecimento e a realização da autonomia individual, isto é, de metas individuais

4. Honneth, A., Anderson, J., "Autonomia, Vulnerabilidade, Reconhecimento e Justiça", p. 88.

5. Honneth, A. Luta por Reconbecimento. A gramática moral dos conflitos sociais. São Paulo: Editora 34, 2003.

6. Honneth, A., Anderson, J., "Autonomia, Vulnerabilidade, Reconhecimento e Justiça", p. 87. 
de vida. Desenvolvimento que até então havia sido apenas sugerido por Honneth, que afirma, em Luta por Reconbecimento:

A "espontaneidade" ou "liberdade" não pode referir-se (...) simplesmente à ausência de coerção ou influência externa, ela significa ao mesmo tempo a falta de bloqueios internos, de inibições psíquicas e de angústias; mas, num sentido positivo, essa segunda forma de liberdade deve ser compreendida como uma espécie de confiança dirigida para fora, que oferece ao indivíduo segurança tanto na expressão das carências como na aplicação de suas capacidades. (...) As formas de reconhecimento do amor, do direito e da solidariedade formam dispositivos de proteção intersubjetivos que asseguram as condições da liberdade externa e interna, das quais depende o processo de uma articulação e de uma realização espontânea de metas individuais de vida. ${ }^{7}$

O artigo "Autonomia, Vulnerabilidade, Reconhecimento e Justiça" representa, nesse sentido, um desenvolvimento de consequências ainda não amplamente exploradas de teses já contidas no modelo crítico de Honneth, principalmente em Luta por Reconbecimento. Nos dois textos, o ponto de partida é o mesmo: os efeitos negativos gerados pelo rompimento das relações de reconhecimento. Porém, enquanto em Luta por Reconbecimento tais rompimentos eram explorados no intuito de mostrar que eles geram um sentimento de desrespeito naqueles que têm suas expectativas morais de reconhecimento frustradas, sentimento que pode por sua vez desencadear lutas por reconhecimento, nesse artigo o objetivo é mostrar que tais rompimentos geram bloqueios à realização da autonomia, algo que permite aos autores a explicitação da dependência, dos indivíduos, de relações de reconhecimento.

Neste artigo, portanto, Honneth e Anderson tiram o foco da motivação moral dos conflitos sociais e o colocam na explicitação das vulnerabilidades associadas ao rompimento das relações de reconhecimento. Com isso, eles enfatizam também a importância de atentar para as vulnerabilidades dos indivíduos, conceito que até então tinha sido usado por Honneth apenas esporadicamente para designar de modo mais amplo a dependência que todos possuem de relações de

7. Honneth, A. Luta por Reconbecimento, p. 273-4. 
reconhecimento. ${ }^{8}$ Partindo então dos prejuízos à autonomia individual gerados pelo rompimento de relações de reconhecimento, Honneth e Anderson procuram reconstruir as três formas de reconhecimento intersubjetivo que têm de ser socialmente garantidas para que os indivíduos sejam autônomos, cada qual vinculada a um tipo específico de vulnerabilidade. Eles buscam, assim, explicitar as vulnerabilidades dos indivíduos contemporâneos e chegar, a partir delas, à estrutura básica de reconhecimento, de cuja efetivação depende a possibilidade de realização da autonomia individual. Ao fazerem isso, os autores visam ressaltar a importância das relações de reconhecimento para a autonomia e reconstruir o que chamam provocativamente de estrutura básica de reconhecimento das sociedades contemporâneas.

Vemos, assim, que embora recusem o escopo limitado das teorias liberais sobre as condições necessárias para a realização da autonomia - dentre as quais a proposta por Rawls -, Honneth e Anderson se apropriam de um conceito utilizado por ele: o de estrutura básica da sociedade. Ao fazerem isso, contudo, os autores procuram pensá-lo de outra forma. Isto é, procuram pensá-lo não a partir de princípios que regulariam uma distribuição justa de bens e de respeito, mas como uma estrutura básica de relações intersubjetivas de reconhecimento. Com base nas três formas de reconhecimento das quais depende a autonomia dos indivíduos, Honneth e Anderson desenvolvem, então, uma teoria normativa da estrutura básica de reconhecimento, a partir da qual explicitam as exigências sociais para a realização de uma sociedade justa, com indivíduos autônomos. Como afirmam os autores:

da perspectiva da pergunta por quais são as condições que garantem igualmente a autonomia pessoal de todos os membros da sociedade e que os protegem igualmente em sua vulnerabilidade intersubjetiva, o principal foco da aplicação dos princípios de justiça passa a ser a estrutura e a qualidade de relações sociais de reconhecimento.

8. Como afirma Honneth em Luta por Reconbecimento, "É do entrelaçamento interno de individualização e reconhecimento, esclarecido por Hegel e Mead, que resulta aquela vulnerabilidade particular dos seres humanos, identificada com o conceito de 'desrespeito': visto que a autoimagem normativa de cada ser humano, de seu 'Me', como havia dito Mead, depende da possibilidade de um resseguro constante no outro, vai de par com a experiência de desrespeito o perigo de uma lesão, capaz de desmoronar a identidade da pessoa inteira." Idem, p. 213-4. 
Como resultado, essa concepção liberal de justiça perde seu caráter de teoria de distribuição. Ela se torna, pelo contrário, - para colocar de uma forma um tanto provocativa - uma teoria normativa da estrutura básica de reconbecimento de uma sociedade. O que vem, então, tomar o lugar dos princípios de distribuição justa são os princípios que governam o modo pelo qual as instituições básicas da sociedade garantem as condições sociais para o reconhecimento recíproco. ${ }^{9}$

De acordo com Honneth e Anderson, portanto, mesmo um autor sofisticado como Rawls teria negligenciado a importância das relações de reconhecimento em sua teoria da justiça. Rawls não procura incluir conhecimentos acerca de necessidades e características humanas básicas, nem trata de "considerações empíricas sobre as vulnerabilidades humanas". ${ }^{10} \mathrm{~A}$ única das três formas de reconhecimento que Rawls leva em conta é a do respeito, um dos bens sociais que teriam de ser distribuídos. Na busca pela imparcialidade e pela universalidade, Rawls desenvolve uma teoria que acaba deixando de lado as particularidades dos seres humanos - algo que, para eles, não é necessariamente "incompatível com um comprometimento com formas inclusivas e universalistas de liberalismo". ${ }^{11}$

Segundo Honneth e Anderson, "a caracterização rawlsiana do véu da ignorância acaba permitindo que o fato da intersubjetividade humana desapareça de vista mais do que o necessário". ${ }^{12}$ Isso o teria impedido de ver quão essenciais as relações de reconhecimento são para a autonomia. Como os liberais em geral, portanto, Rawls acaba não tratando da importância das relações de reconhecimento para o estabelecimento de autorrelações práticas positivas, além de impedir - com o artifício do "véu da ignorância" - que elas sejam tematizadas. Limitações que, segundo Honneth e Anderson, só podem ser superadas com concepções de autonomia e de estrutura básica da sociedade atentas às vulnerabilidades relacionais dos indivíduos. Nesse sentido, somente a abordagem baseada no reconhecimento desenvolvida por eles daria conta de sanar as dificuldades geradas pelas concepções liberais de autonomia.

9. Honneth, A., Anderson, J., "Autonomia, Vulnerabilidade, Reconhecimento e Justiça", p. 107-8.

10. Idem, p. 103.

11. Idem, p. 105.

12. Idem, p. 102. 
Ao procurarem resolver as dificuldades que identificam no interior do liberalismo, contudo, os autores acabam se aproximando mais do modelo liberal do que parecem, num primeiro momento, assumir. Afinal, ainda que se afastem do individualismo típico do liberalismo, eles pensam as condições sociais requeridas para a autonomia e para a justiça a partir de pressupostos liberais. Nesse artigo, o ponto de partida de Honneth e Anderson parece ser o de que, tendo em vista a pluralidade de metas individuais, o único fim unânime e, portanto, legítimo a ser perseguido é o de garantir que cada um possa seguir suas próprias metas individuais. Eles constroem seu argumento com base no pressuposto liberal de que uma sociedade justa é aquela que garante ao indivíduo "o direito de perseguir seus objetivos livremente, protegido contra a interferência dos outros" ${ }^{\prime \prime}{ }^{13}$ A divergência entre o liberalismo, assim caracterizado, e a posição defendida por Honneth e Anderson está em quais são as condições sociais requeridas pela autonomia, mais do que no significado da própria autonomia, entendida por ambos como a possibilidade de perseguir metas individuais de vida.

A normatividade da teoria de Honneth e Anderson não é, portanto, extraída das lutas político-democráticas, mas sim das carências - vinculadas a relações intersubjetivas de reconhecimento - que têm de ser sanadas para que os indivíduos possam escolher quais caminhos trilhar. Ainda que explicitem a importância da intersubjetividade e enfatizem, contra os liberais, que a própria formação da individualidade depende diretamente de relações sociais de reconhecimento, essa intersubjetividade é pensada a partir de um "âmbito privado" e não, por exemplo, a partir de procedimentos democráticos de justificação. O foco de "Autonomia, Vulnerabilidade, Reconhecimento e Justiça" parece, assim, recair sobre a garantia da autonomia privada dos cidadãos.

As críticas que Honneth e Anderson procuram desferir ao viés individualista do liberalismo têm em vista o debate que se estabeleceu entre liberais e comunitaristas sobre a importância da comunidade e das interações sociais para a formação do indivíduo. Se tomamos, contudo, as consequências da posição defendida por eles, tendo agora no horizonte o debate entre liberais e republicanos, Honneth e

13. Manin, B. "Legitimidade e Deliberação Política". In: Melo, R., Werle, D. (orgs.) Democracia Deliberativa. São Paulo: Esfera Pública, 2007, pp. 16-7. 
Anderson parecem, ao contrário, se aproximar dos primeiros. Afinal, ainda que as lutas políticas desempenhem um importante papel no interior da teoria do reconhecimento de Honneth, como Luta por Reconbecimento deixa bastante claro, elas são centrais na medida em que garantem a expansão de relações de reconhecimento, das quais depende a formação não distorcida da identidade do indivíduo e sua capacidade de conduzir a vida que determinou como digna de valor. É a partir de uma preocupação com a autonomia privada e não com a autonomia pública que Honneth e Anderson reconstroem aquilo que tomam, nesse artigo, como as condições sociais para a autonomia e para a própria justiça.

Como consequência, parece possível afirmar que as próprias lutas por reconhecimento possuem, para esses autores, um caráter pré-político. Elas não decorrem da divergência pré-política entre interesses privados distintos, como em muitas teorias liberais da democracia ${ }_{1}^{14}$ mas estão diretamente vinculadas à necessidade pré-política dos indivíduos de estarem amparados por relações recíprocas de reconhecimento em três diferentes esferas. A garantia da autonomia pessoal e da própria justiça são pensadas a partir das condições sociais que permitem ao indivíduo conduzir a vida que determinou como boa. Com isso, os autores relegam à autonomia pública, atrelada a processos deliberativos de formação política da opinião e da vontade, um papel secundário. Consequência que acaba por explicitar alguns dos pontos em que a posição de Honneth e Anderson se distingue daquela sustentada pelos defensores de um modelo deliberativo de democracia, como Habermas, para quem autonomia pública e privada são cooriginárias. ${ }^{15} \mathrm{O}$ artigo aqui traduzido acaba, nesse sentido, explicitando a proximidade da posição de seus autores com o liberalismo.

\section{Referências bibliográficas:}

ANDERSON, J., CHRISTMAN, J. Autonomy and the Challenges to Liberalism. New Essays. Cambridge: Cambridge University Press, 2005.

14. Cf. Nobre, M. "Participação e Deliberação na Teoria Democrática: uma Introdução". In: Nobre, M., Coelho, V. (org). Participação e Deliberação. São Paulo: Editora 34, 2004, pp. 31-40.

15. Habermas, J. A Inclusão do Outro. Estudos de teoria política. São Paulo: Loyola, 2007, caps. 9 e 10. Habermas, J. Direito e Democracia. Entre facticidade e validade. Rio de Janeiro: Tempo Brasileiro, 2003, cap. 3. 
Nathalie Bressiani

HABERMAS, J. Direito e Democracia. Entre facticidade e validade. Rio de Janeiro: Tempo Brasileiro, 2003.

HABERMAS, J. A Inclusão do Outro. Estudos de teoria política. São Paulo: Loyola, 2007.

HONNETH, A. Luta por Reconbecimento. A gramática moral dos conflitos sociais. São Paulo: Editora 34, 2003.

HONNETH, A., ANDERSON, J., "Autonomia, Vulnerabilidade, Reconhecimento e Justiça". In: Cadernos de Filosofia Alemã. Crítica e Modernidade, v. 17, jan-jun de 2011.

MANIN, B. "Legitimidade e Deliberação Política". In: MELO, R., WERLE, D. (orgs.) Democracia Deliberativa. São Paulo: Esfera Pública, 2007.

MARSHALL, T. Cidadania, Classe Social e Status. Rio de Janeiro: Zahar Editores, 1969.

NOBRE, M. "Participação e Deliberação na Teoria Democrática: uma Introdução". In: NOBRE, M., COELHO, V. (orgs). Participação e Deliberação. São Paulo: Editora 34, 2004.

RAWLS, J. Uma Teoria da Justiça. São Paulo: Martins Fontes, 2002. 